\title{
Trichorhinophalangeal syndrome type 1 and 3
}

INSERM

\section{Source}

INSERM. (1999). Orphanet: an online rare disease and orphan drug data base.

Trichorhinophalangeal syndrome type 1 and 3. ORPHA:77258

Trichorhinophalangeal syndromes (TRPS) type 1 and 3 are malformation syndromes characterized by short stature, sparse hair, a bulbous nasal tip and cone-shaped epiphyses, as well as severe generalized shortening of all phalanges, metacarpals and metatarsal bones. 